\section{Lucien Maurice Levy}

D r Lucien Levy passed away December 19, 2013, peacefully at his home in Columbia, Maryland. News spread within hours to the entire George Washington University family, and the abruptness and shock of it quickly moved from the nation's capital to the world of neuroradiology, which mourns the loss of an exceptional colleague and friend.

Lucien completed his undergraduate studies at McGill University in 1967, after earning his electrical engineering degree with honors and continued at the Massachusetts Institute of Technology, studying under Dr William Daggett in the cardiovascular unit and earning a doctorate in biomedical and electrical engineering in 1973. Lucien completed a Doctor of Medicine degree at Johns Hopkins University in 1981 and a neuroimaging fellowship under Dr Giovanni DiChiro at the National Institutes of Health and became an attending radiologist at Hopkins under Dr Nick Bryan. Lucien's academic career continued in Washington, DC, as an attending radiologist at Georgetown University for 5 years and thereafter as Professor of Radiology at The George Washington University since 1999. Lucien's final publications “MR Imaging of Papilledema and Visual Pathways: Effects of Increased Intracranial Pressure and Pathophysiologic Mechanisms" (2013;34:919-24) and "Pseudotumor Cerebri: Brief Review of Clinical Syndrome and Imaging Findings" (2013;34:919-24) appeared in the American Journal of Neuroradiology (AJNR). He served as a Senior Editor of $A J N R$ since 2007 and was an Associate Editor of $R a$ diology since 2009. During his tenure with $A J N R$, he proved to be a conscientious, acute, and fair editor. He took pride in his work and always offered new ideas. His breadth of knowledge was spectacular, and as Editor Emeritus of AJNR, Dr Robert Quencer once said, "One could learn more from reading Lucien's evaluations than from the actual articles he was reviewing."

Lucien loved teaching, and this attracted neuroradiology fellows who sought his mentorship to The George Washington University from as far away as India, Iraq, and Israel. Lucien continued to teach residents, fellows, and students during his brave fight with colon cancer. Last year, the George Washington radiology residents honored him with the Golden Apple

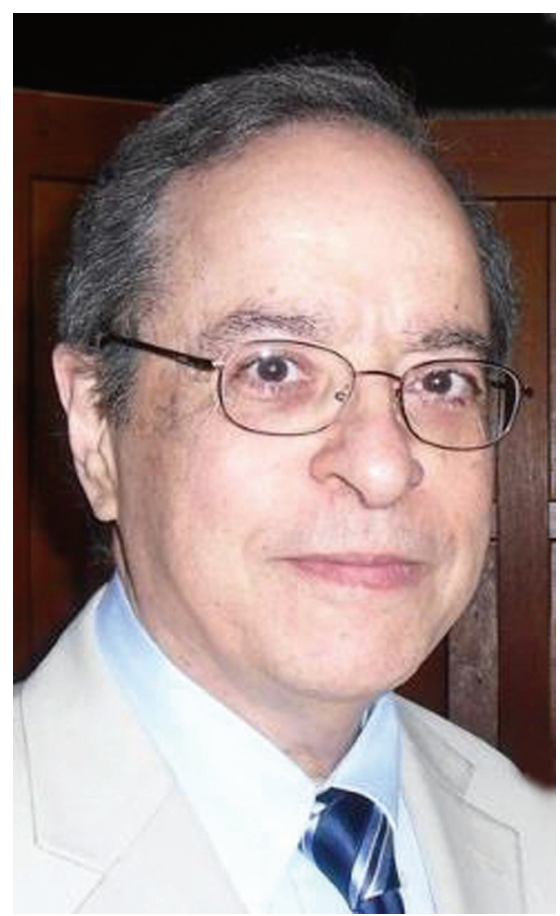

Award for teaching excellence, an award that he treasured. A few days before his passing, he was happy to hear the good news that all of his senior residents had passed the recent American Board of Radiology resident examination. Lucien will be remembered for his wit and humor. He had the knack of engendering smiles from all of those whom he mentored, even on the most mundane of subjects. All of us who knew Lucien had a rare opportunity to work with such a special, unassuming, quiet, and private man. He will be missed immensely in the reading room and by his $A J N R$ colleagues, his family, his trainees, and all those who encountered him.

R.K. Tu

R. Bhojwani

R. Taheri M. Monteferrante

A. Ahmad Neuroradiology Section The George Washington University Washington, DC

http://dx.doi.org/10.3174/ajnr.A3881 